\title{
The Relationship between Basic Psychological Needs, Depression, Anxiety and Stress in Students from Urban India
}

\author{
Cicilia Chettiar \\ Head, Department of Psychology, Maniben Nanavati Women's College, Mumbai \\ E-mail - ciciliachettiar@yahoo.com \\ Corresponding Author - Cicilia Chettiar
}

\begin{abstract}
Background: The current study was an attempt to understand the relationship between basic needs as identified by self-determination theory, negative states of depression, anxiety and stress and well being in students from urban India. It was developed around the framework of basic psychological needs theory which is a part of self-determination theory.

Hypothesis: It was hypothesized that there will be statistically significant correlation between those who have higher well being and satisfaction of the three basic psychological needs and this will be positive. It was also hypothesized that there will be a negative but statistically significant correlation between those who have lower well being and who show higher scores on depression, anxiety and stress.

Results: Pearson's product-moment correlation was used to arrive at these results and they were computed separately for males and females in the sample. A gender based comparison of depression, anxiety and stress indicated a statistically significant difference between both. Implications of the study are discussed.
\end{abstract}

Key words: basic psychological needs, depression, anxiety, stress, students.

(Paper received $-9^{\text {th }}$ September 2017, Peer review completed $-29^{\text {th }}$ September 2017)

(Accepted $-6^{\text {th }}$ October 2017)

\section{INTRODUCTION}

Students in India are exposed to myriad challenges that affect their well being. There are increasing number of cases of depression, anxiety and even suicide amongst the student population [1]. This is not just restricted to particular courses or streams that have highly intensive programs. It appears to be common across all streams. At times it seems as if the presence of an academic life is what causes the students to experience much distress [2].

Indian parents tend to pay a very high premium on education and follow the normative structure when it comes to planning one's life. Culturally too, Indian parents have a lot more say in the choices that their children make, be it academic or personal. Perhaps it is this additional influence, perhaps it is peer pressure, perhaps it just developmental life issues; whatever it is, students are in anguish [3].

The educational procedures and policies also lead to much uncertainty and consequent confusion. For a young adolescent who steps out into the world with dreams of making a difference to the world, of making life better for self and others, he is repeatedly bombarded with challenges that he is neither equipped nor trained to handle [4]. Late adolescence is also a period of much introspection, adventure, hormonal changes and other developmental milestones. The complications of daily living along with the pressure of academia sometimes become too much for students and they collapse. It would be wonderful if this situation could be prevented rather than treated after things have gotten really bad. Identifying problem areas, vulnerable populations and then reaching out in support would reduce a lot of social ills and ensure 
that the nation receives a well-adjusted citizenry that can raise the standards of the nation to greater heights [5-6].

One of the first steps is in identifying students who are vulnerable and then providing appropriate treatments. Along with screening students to understand their current mental states, it would also be very useful to identify the correlates of well being and ill-being.

\section{Well Being}

Subjective well being or SWB as it is commonly known refers to the experience of wellness by the individual [7]. Diener refers to it as the way people experience the quality of their lives in terms of both emotional reactions and cognitive judgments. The study of SWB has garnered a lot of attention in the psychology over the past few decades [8]. This in large part is due to the popularity of positive psychology and the need to study strengths rather than weaknesses. Such studies have been carried out across different cultures, age-groups and contexts. Its influence on personality using the big five theory showed that openness to experience, extraversion and neuroticism are the most important correlates to SWB [9].

Diener in his review on the progress of SWB across three decades predicted that the interaction of life circumstances with psychological factors would be the future of SWB research. Most studies in reality also did pursue this path. Rather than focusing on merely demographic variables in an attempt to identify the correlates of SWB, later researchers focused on context specific studies to understand SWB. Hence we have had a wide range of studies across the globe [10]. The current study reinforces this premise and attempts to understand precisely how a particular life circumstance impacts the presence or absence of well-being in question.

\section{Basic Psychological Needs}

The combination of pressure to prove and limited availability of the resources challenge fundamental psychological needs in an individual that has an overall impact on well-being [10]. Self-determination theory [11] states that satisfaction of the psychological needs for autonomy, relatedness and competence are crucial for the experience of psychological well being. According to them, autonomy refers to the experience of being the person in charge of one's action. The need for competence is similar to effectance motivation, in that it allows for the perception of being the agent that can influence the environment enough to effect a change in it as per one's need [12]. The concept of relatedness refers to the interpersonal associations formed and the extent of closeness to significant others in life. Unlike other theories of motivation that focus on the strength of needs, this theory focuses on the extent to which these needs are satisfied. An environment that provides for greater need satisfaction will also enable greater well-being [13]. The current population of interest for this study appears to be challenged on all three needs. What should have been a life challenge turns into a life-altering experience which is for the most part unpleasant. Although education is a basic and essential part of life, many students these days seem to experience it as a burden and have serious mental health issues due to their academic conditions. According to Deci and Ryan [11], non-fulfillment or partial fulfillment of basic psychological needs will lead to lack of well being. These needs can also be fulfilled if the right conditions are made available and this will naturally lead to an improvement in well being.

\section{Depression, Anxiety \& Stress}

Anxiety, stress and depression are all negative states of being and the difference between the three is one of kind and not of degree. Stress is usually a reaction to an unpleasant stimulus. It's the load placed on the body due to something or someone in the environment that drains the individual of coping resources. Even if the load is mental in nature, stress is accompanied by major physical changes. Anxiety is a feeling of apprehension in the absence of a negative stimulus. It's more cognitively based and is due largely to the thoughts of what might go wrong. It is a pattern of thinking that allows one to be based in the future [1415]. There is usually a significant overlap between some types of anxiety disorder and major depression. The diagnosis is usually dependent on the patient's report of symptoms and if the clinician is not too alert, one may be diagnosed in place of another. Depression is a mood disorder that in its mildest forms is 
sometimes referred to as "feeling blue." When these blues continue for a specified period with a certain level of severity, the diagnosis for depression is applied [16-17].

\section{Need for the study}

A larger goal for this study was to inform policy makers of the need to look beyond material sustenance when looking at the well being of the student population. As others have pointed out, SWB can impact objective outcomes like health, job success and overall psychological health.

The study therefore sets out to answer the following questions:

1) Are there any gender differences in the variables under study?

2) Is there any correlation between the variables measuring psychological needs, depression, anxiety and stress?

3) Is there any correlation between the variables of WB and all other variables?

\section{METHODOLOGY}

Purposive sampling was used to reach out to the appropriate sample. Prior to data collection, prospective aspirants were contacted through their describing the study and their consent for the same will be taken. The total time period for answering the questionnaire did not exceed 90 minutes. The participants were also allowed to respond to the questionnaire in a maximum of two sessions.

\section{Sample}

Data was collected by in person by administering the questionnaires in a group setting. The participants were given the freedom to opt out of the study at any point while answering the questionnaire. The sample included 161 females and 179 males in the age group of 19-23 years. They were all in various undergraduate programs with a mix of the different streams like arts, science, commerce, engineering, architecture, law etc. There were 101 females and 95 males living with their family and the others were outstation students. The fathers of both males and females were largely employed and the mothers were largely homemakers.

The following questionnaires will be used:

1. Basic Psychological Needs Scale - General: This is a 21-item scale which measures the extent to which individual needs are satisfied [18].

2. Depression Anxiety Stress Scales - The essential function of the DASS is to assess the severity of the core symptoms of Depression, Anxiety and Stress. Accordingly, the DASS allows not only a way to measure the severity of a patient's symptoms but a means by which a patient's response to treatment can also be measured [19].

3. According to OECD's [20] guidelines, well being can be measured across 11 domains ranging from income, job, health, skills, housing, civic engagement and environment. Taking into account existing literature and the benefits of a culturally sensitive tool, the researchers felt the Subjective Well Being Inventory (SWBI) [21] would be the most appropriate tool for this population. It consists of a set of 40 items normed across the country and measuring 11 domains of well-being. Only the component of positive well being (PWB) was used for purposes of this study.

\section{STATISTICAL ANALYSIS}

Descriptive statistical scores were arrived at and Pearson's product moment correlations were computed separately for males and females. A simple t-test was conducted to see if there was any statistically significant difference between males and females for all the psychological variables. 


\section{RESULTS}

It was found that males and females differed significantly on their scores for depression, anxiety and stress with females showing higher scores on all three. Further analysis was carried out separately for males and females. Based on the scoring of the DASS - 21 it can be said that on an average, female students experienced mild depression $(\mathrm{M}=10.88, \mathrm{SD}=8.53)$ and moderate levels of anxiety $(\mathrm{M}=12.58, \mathrm{SD}=7.91)$ in the sample studied. A further break down of the relationship between the variables is provided according to gender in Table 1.

Table 1 - Showing the gender based differences on all measured psychological variables using the t-test

\begin{tabular}{|c|c|c|c|}
\hline Variables & $\mathbf{t}$ & df & Sig. (2-tailed) \\
\hline DEP & 2.449 & 338 & $0.015^{*}$ \\
\hline ANXIETY & 2.494 & 338 & $0.013^{*}$ \\
\hline STRESS & 2.941 & 338 & $0.003^{*}$ \\
\hline PWB & -0.994 & 338 & 0.321 \\
\hline NWB & -1.382 & 338 & 0.168 \\
\hline WB & 1.034 & 338 & 0.302 \\
\hline AUTO & -0.340 & 338 & 0.734 \\
\hline COMP & 0.396 & 338 & 0.693 \\
\hline RLTD & -1.389 & 338 & 0.166 \\
\hline
\end{tabular}

Males (As indicated in Table 2)

1. Increased levels of satisfaction in any one of the three psychological needs were associated with increased satisfaction of the other two needs (Needs of autonomy, competence and relatedness).

2. When autonomy, competence and relatedness needs were not satisfied depression was higher.(Graph 1)

3. When autonomy, competence and relatedness needs were satisfied there was greater positive well being. (Graph 2).

4. Lowered relatedness was related to increased anxiety.

5. Increase in any one negative state was accompanied by increase in the other two negative states (depression, stress and anxiety).

6. Positive well being was low when depression or stress was high.

Table 2 - Overall correlations between all measured psychological variables for males

\begin{tabular}{|l|l|l|l|l|l|l|l|}
\hline & DEP & ANXTY & STRESS & PWB & AUTO & COMP & RLTD \\
\hline DEP & 1 & & & & & & \\
\hline ANXTY & $.633^{* *}$ & 1 & & & & & \\
\hline STRESS & $.733^{* *}$ & $.668^{* *}$ & 1 & & & & \\
\hline PWB & $-.366^{* *}$ & -.106 & $-.216^{* *}$ & 1 & & & \\
\hline AUTO & $-.207^{* *}$ & -.099 & -.097 & $.316^{* *}$ & 1 & & \\
\hline COMP & $-.232^{* *}$ & .018 & -.018 & $.311^{* *}$ & $.472^{* *}$ & 1 & \\
\hline RLTD & $-.216^{* *}$ & $-.177^{*}$ & -.124 & $.360^{* *}$ & $.340^{* *}$ & $.401^{* *}$ & 1 \\
\hline
\end{tabular}




\section{Females}

1. Increased levels of satisfaction in any one of the three psychological needs were associated with increased satisfaction of the other two needs (Needs of autonomy, competence and relatedness).

2. When autonomy, competence and relatedness needs were not satisfied depression, anxiety and stress were higher.

3. When autonomy, competence and relatedness needs were satisfied there was greater positive well being. (Graph 2)

4. Increase in any one negative state was accompanied by increase in the other two negative states (depression, stress and anxiety).

5. Positive well being was low when depression, anxiety or stress was high (Graph 3).

Table 3 - Overall correlations between all measured psychological variables for females

\begin{tabular}{|c|c|c|c|c|c|c|c|}
\hline & DEP & ANXTY & STRESS & PWB & AUTO & COMP & RLTD \\
\hline DEP & 1 & & & & & & \\
\hline ANXTY & $.639^{* *}$ & 1 & & & & & \\
\hline STRESS & $.788^{* *}$ & $.680^{* *}$ & 1 & & & & \\
\hline PWB & $-.554^{* *}$ & $-.339^{* *}$ & $-.482^{* *}$ & 1 & & & \\
\hline AUTO & $-.474^{* *}$ & $-.205^{* *}$ & $-.290^{* *}$ & $.468^{* *}$ & 1 & & \\
\hline COMP & $-.444^{* *}$ & $-.250^{* *}$ & $-.323^{* *}$ & $.512^{* *}$ & $.454^{* *}$ & 1 & \\
\hline RLTD &.$- .307^{* *}$ & $-.173^{*}$ & $-.256^{* *}$ & $.510^{* *}$ & $.348^{* *}$ & $.264^{* *}$ & 1 \\
\hline
\end{tabular}

\section{Combined Sample}

Overall, there is a significant difference in the depression levels of males $(\mathrm{M}=8.61, \mathrm{SD}=8.52)$ and females $(\mathrm{M}=10.88, \mathrm{SD}=8.53)$. Similar differences are observed in anxiety and stress with females scoring higher on all three parameters as indicated in Table 3. There was an inverse relationship between PWB and depression, anxiety and stress (Graph 3).

Graph 1 - Relationship between need satisfaction and negative psychological states in males and females

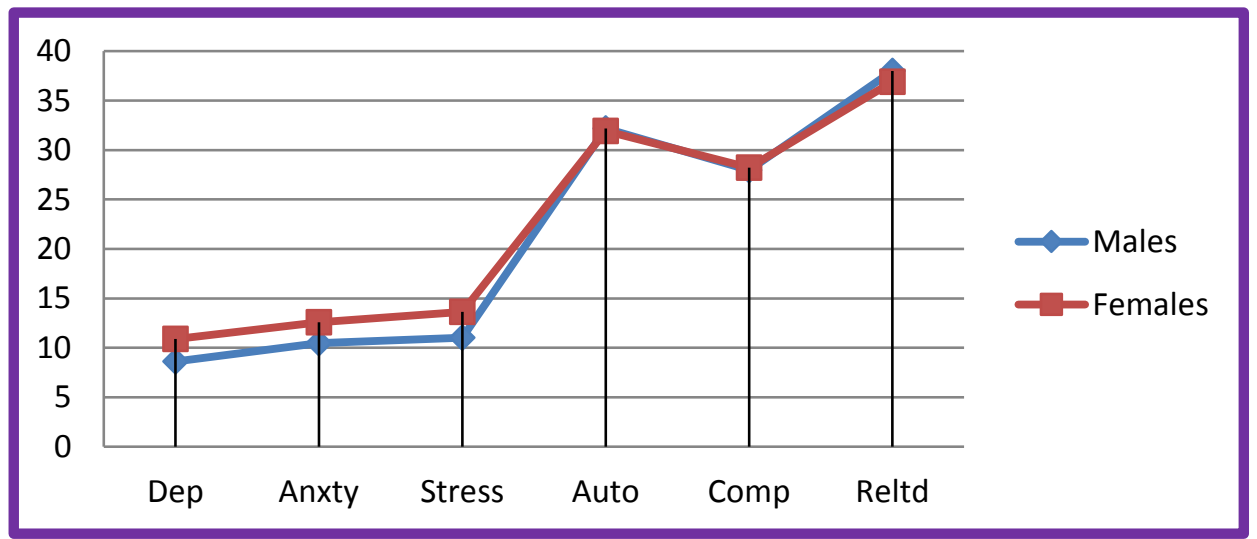

\section{DISCUSSION}

In this study however, in spite of the technical differences in definition, it was found that those who were stressed were also depressed and anxious. This finding was true for both males and females.

The test used to identify a state of well being in this study focused purely on positive well being (PWB). The effects of this variable are stable across time and hence should be emphasized when attempting to evaluate well being. The obvious result of this study is that men and women have different ways of 
perceiving the world and adapting to it. Hence it is imperative that any kind of intervention to increase well being should take into account the gender of the student.

Graph 2 - Relationship between satisfaction of needs and PWB in the combined sample

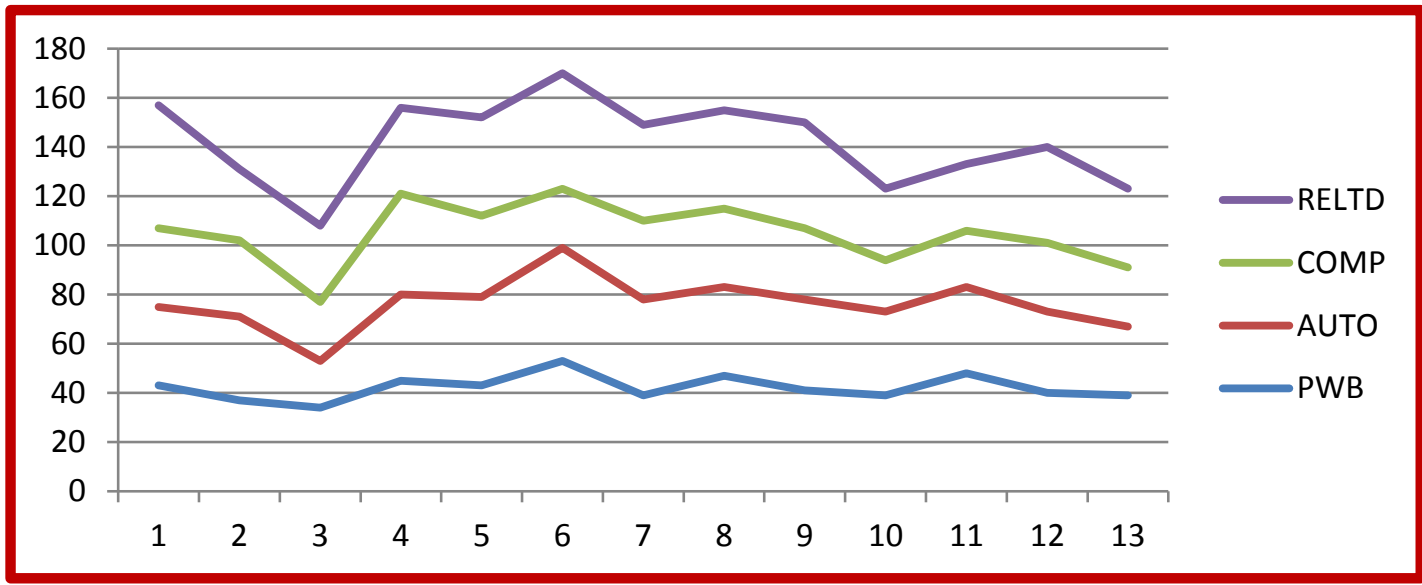

Graph 3 -Inverse relationship between Depression, Stress, Anxiety and PWB in the combined sample

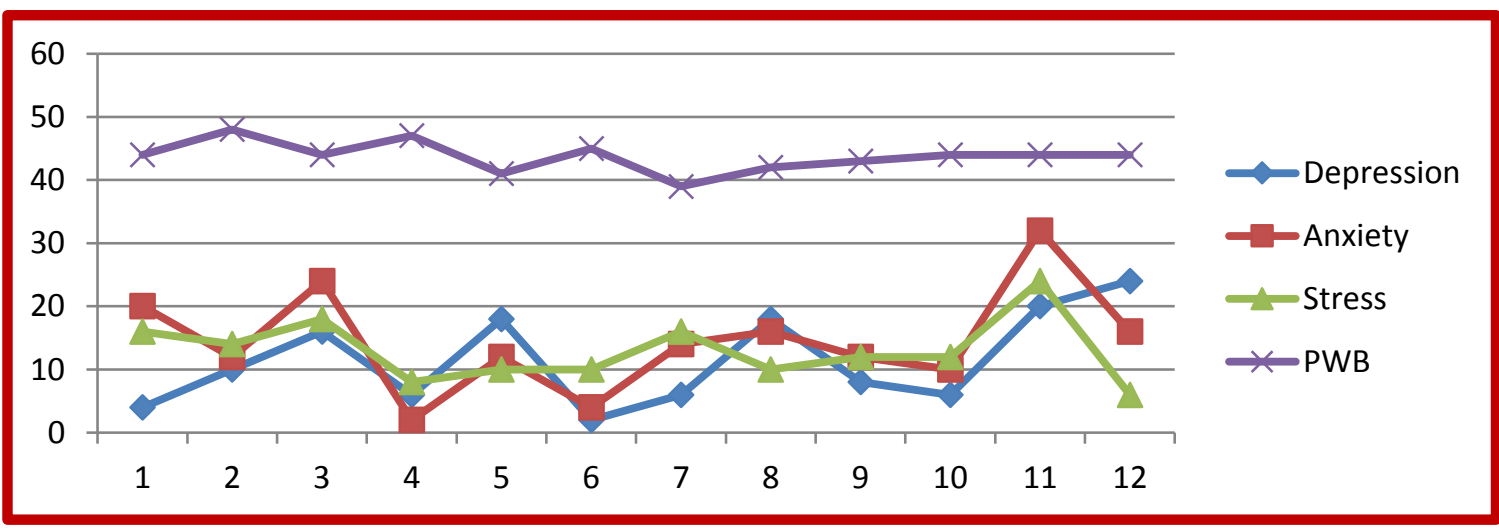

In both genders satisfaction of the needs of autonomy competence and relatedness leads to more positive states of well being. All the three needs if not satisfied will be accompanied by depression, anxiety and stress. The gender difference in the occurrence of stress and anxiety could be a reflection of the cultural norms that provide greater autonomy to men than to men. India is a traditionally conservative country with clear gender defined roles. Although the sample comes from an urban setting, it reflects traditional gender based expectations and hence should be considered when reflecting on the implications of the study. The lack of a statistically significant difference in the scores for satisfaction of the three needs indicate that both genders perceive the level of need satisfaction similarly. However the impact of the negative states of mind for both genders is different [22].

Males are likely to experience depression when autonomy, competence or relatedness needs are not met. However when relatedness needs are not met, they also experience anxiety. This is insightful as it appears that men find the ability to use their affiliations to deal with their anxiety. Traditionally, this was believed to be more representative of females and males were expected to be less affected by affiliation needs. The stereotype of the strong, silent, stoic male appears to be cracking. This is particularly relevant in the Indian context as it shows a change in the gender defined coping strategy. The experience of stress does not seem to be affected by change in any of the three needs and is clearly negatively correlated with a positive state of mind [23]. 


\section{Recommendations}

Based on the analyses and interpretations discussed above, it can be said that well being can be developed by -

1. Providing conditions that fulfill the needs for autonomy, competence and relatedness.

2. Autonomous conditions can be created by providing greater choice and the freedom to make their own decisions

3. Competence can be affected by providing the freedom to be in control of our own environment

4. Relatedness occurs when one feels understood, appreciated, connected to and cared for by others.

\section{Limitations}

This study is subject to the limitations of all similar studies with a self report nature, namely, social desirability. More research should be conducted in other institutes to confirm whether this is a random or justified result.

\section{REFERENCES}

1. Augustine LF, Vazir S, Rao SF, Rao MV, Laxmaiah A, Nair KM. Perceived stress, life events \& coping among higher secondary students of Hyderabad, India: A pilot study. Indian J Med Res 2011;134(1):61-8.

2. Verma S, Sharma D, Larson RW. School stress in India: Effects on time and daily emotions. Int J Behav Dev 2002;26(6):500-8.

3. Santor DA, Messervey D, Kusumakar V. Measuring peer pressure, popularity, and conformity in adolescent boys and girls: Predicting school performance, sexual attitudes, and substance abuse. J Youth Adolesc 2000;29(2):163-82.

4. Deb S, Chatterjee P, Walsh K. Anxiety among High School Students in India: Comparisons across Gender, School Type, Social Strata and Perceptions of Quality Time with Parents. Austr J Educn Dev Psychol 2010;10:18-31.

5. Archer SL. Interventions for adolescent identity development. Sage Publications, Inc; 1994.

6. Silbereisen RK, Lerner RM. Approaches to positive youth development. Sage; 2007.

7. Diener E, Suh EM, editors. Culture and subjective well-being. MIT press; 2000.

8. Diener E, Diener M, Diener C. Factors predicting the subjective well-being of nations. J Personal Soc Psychol 1995;69(5):851-64.

9. Gutierrez JL, Jimenez BM, Hernández EG, Pcn C. Personality and subjective well-being: Big five correlates and demographic variables. Personal Individ Diff 2005;38(7):1561-9.

10. Diener E, Suh EM, Lucas RE, Smith HL. Subjective well-being: Three decades of progress. Psychol Bull 1999;125(2):276-98.

11. Deci EL, Ryan RM. The" what" and" why" of goal pursuits: Human needs and the self-determination of behavior. Psychol Inquiry 2000;11(4):227-68.

12. Waytz A, Morewedge CK, Epley N, Monteleone G, Gao JH, Cacioppo JT. Making sense by making sentient: effectance motivation increases anthropomorphism. J Personal Soc Psychol 2010;99(3):410-35.

13. Triandis HC. Interpersonal behavior. Brooks/Cole Pub. Co.; 1977.

14. Beck A, Emery G, Greenberg RL. Anxiety disorders and phobias: A cognitive perspective. Basic Books; 2005.

15. Craske MG. Anxiety disorders: psychological approaches to theory and treatment. Boulder, CO, US: Westview Press; 1999.

16. Martell CR, Addis ME, Jacobson NS. Depression in context: Strategies for guided action. WW Norton \& Co; 2001.

17. Blatt SJ. Experiences of depression: Theoretical, clinical, and research perspectives. American Psychological Association; 2004.

18. Wei M, Shaffer PA, Young SK, Zakalik RA. Adult attachment, shame, depression, and loneliness: The mediation role of basic psychological needs satisfaction. J Couns Psychol 2005;52(4):591-601.

19. Lovibond PF, Lovibond SH. The structure of negative emotional states: Comparison of the Depression Anxiety Stress Scales (DASS) with the Beck Depression and Anxiety Inventories. Behav Res Ther 1995;33(3):335-43.

20. Helliwell JF, Layard R, Sachs J. World happiness report 2013. 
21. Kahneman D, Krueger AB. Developments in the measurement of subjective well-being. J Econ Perspect 2006;20(1):3-24.

22. Nolen-Hoeksema S. Gender differences in depression. Curr Dir Psychol Sci 2001;10(5):173-6.

23. Matud MP. Gender differences in stress and coping styles. Personal Individ Diff 2004;37(7):1401-15.

$* * * * * * * * * * * * * * * * * * * * * *$

\section{Acknowledgements}

1. Dr. Dhaval Mody and Ms. Supriya Das for collaborating on the project

2. Dr. Poonam Sharma and Ms. Rekha Wagani from Department of Psychology, Amity University for facilitating the data collection from their college.

3. Soham Consultancy for statistical analysis.

\section{Source of Funding}

RoundGlass H20 Pvt Ltd., IT C-7 KMG Tower, $2^{\text {nd }}$ floor, Sector 67, SAS Nagar, Mohali - 1600062, Punjab.

Conflict of Interest - Nil 